\title{
Mineração
}

\section{Desgaste na mineração: o caso dos corpos moedores}

\author{
Monica Speck Cassola \\ PhD em Enga Mineral \\ Instituto de Pesquisas Tecnológicas do Estado de São Paulo S/A. E-mail:mrnc@ipt.br
}

Sandra Lúcia de Moraes

MSc. em Eng ${ }^{a}$ Mineral

Instituto de Pesquisas Tecnológicas do Estado de São Paulo S/A. E-mail: sandralm@ipt.br

Eduardo Albertin

PhD em Eng ${ }^{a}$ Metalúrgica

Instituto de Pesquisas Tecnológicas do Estado de São Paulo S/A. E-mail: albertin@ipt.br

\section{Resumo}

Os pesquisadores do IPT desenvolveram knowhow para correlacionar os resultados laboratoriais de ensaios de desgaste de corpos moedores diretamente à indústria, por meio de constantes pesquisas e trabalhos realizados em parceria com o setor mínero-metalúrgico. Os ensaios padronizados em escala-piloto, com diferentes tipos de bolas de moinho, de ferros fundidos brancos de alto cromo e de aços temperados, nos quais avaliam-se as taxas e os micromecanismos de desgaste destas, fornecem uma correlação quantitativa direta com os resultados industriais. O presente trabalho teve como objetivo a caracterização dos corpos moedores para avaliação desse insumo adquirido de diferentes fornecedores para dar subsídio técnico às unidades de moagem industriais. As principais etapas foram: Determinação das curvas de polarização (avaliação do efeito de corrosão preferencial), Caracterização metalográfica (caracterização química e metalográfica das amostras de bolas) e Ensaio de desgaste (avaliação do desgaste dos corpos moedores em unidade-piloto contínua de moagem e classificação). Os resultados obtidos permitiram elaborar uma hierarquia de desempenho técnico.

Palavras-chave: cominuição, corpos moedores, desgaste.

\begin{abstract}
The Division of Metallurgy of IPT has been working for some years in studies of grinding media wear. Tests have been conducted using phosphate and iron ores, as well as quartz sand, representing the range of abrasivity usually found in practical applications. The pilot plant scale testing program was carried out testing balls made of steel and of different types of high chromium white cast irons, evaluating the wear rates and analyzing the wear micromechanisms of these balls. In that work, the objective was the validation of the wear evaluation method, comparing the results obtained in an industrial ball mill, grinding phosphate ore with those obtained running continuously the pilot-scale laboratory mill. Quantitative correlations between the perfomance of the grinding media in the industrial and the laboratory ball mills were obtained. The present work had for objective the characterization of the grinding media for evaluation of balls acquired from different suppliers. The main stages were: Determination of the polarization curves (evaluation of the preferential corrosion's effect), Metallographic characterization (chemical and metallographic characterization of the balls samples) and Wear tests (to evaluate the wear of the grinding media in a continuous milling and classification pilot scale plant). The results obtained allowed to elaborate a ball wear rate ranking. The final result is a validated testing method available for the industry to foresee the wear of grinding media for each type of ore, making possible the selection of suppliers as well as the development of the best alloy for each case, aiming to lower costs in the grinding process.
\end{abstract}

Keywords: comminution, grinding media, wear. 


\section{Introdução}

Considera-se, geralmente, que o consumo de corpos moedores é um dos principais itens de custo no processamento de minérios. Na indústria de cimento, as bolas de moinho de ferro fundido branco de alto cromo (FFBAC) tornaram-se o padrão, em vista de um desempenho nitidamente superior em comparação com bolas de aço fundidas ou forjadas. Já, no caso de moagem a úmido de minérios e, de maneira geral, nas condições mais severas do ponto de vista do desgaste, as diferenças de desempenho entre os materiais tende a diminuir, o que torna necessário analisar, caso a caso, as eventuais vantagens técnicas e econômicas, ao selecionar o tipo de corpo moedor e respectivos material e processo de fabricação.

Devido ao seu grande potencial como material resistente ao desgaste em aplicações na indústria de processamento de minérios, foram realizados muitos estudos em todo o mundo sobre os ferros fundidos brancos de alto cromo. Entretanto a colocação, em prática, de desenvolvimentos relativos a materiais resistentes ao desgaste é dificultada pelo fato de que resultados de ensaios de laboratório, em que as condições de interação abrasivo/metal diferem muito daquelas encontradas na prática, tendem a ser pouco aceitos como indicadores do desempenho desses materiais nos equipamentos de moagem industrial.

Por outro lado, os ensaios de corpos moedores, em condições de produção industrial, são demorados e onerosos, tanto para os fornecedores desses insumos, como para os usuários. Além disso, do ponto de vista metodológico, apresentam sérios problemas, no que se refere ao controle das condições experimentais, já que não há a possibilidade prática de priorizar a manutenção de condições constantes da operação - essenciais para uma efetiva comparação de desempenho - em detrimento das necessidades da produção. É praticamente inviável, nessas condições, manter sob controle todas as variáveis que podem afetar os resultados.
A disponibilidade de um ensaio relativamente barato e rápido, capaz de reproduzir, pelo menos parcialmente, as condições de um moinho de bolas industrial, pode contribuir para o desenvolvimento dos materiais para corpos moedores, bem como dotar os usuários de uma ferramenta eficiente para o controle de qualidade desse insumo essencial. Um bom ensaio de desgaste deve atender a três requisitos: reprodutibilidade, capacidade de estabelecer uma hierarquia de desempenho (ranking) e transferibilidade para a prática verificada através dos resultados em serviço. A literatura apresenta três abordagens, no que se refere ao estudo de materiais para corpos moedores, que estão apresentados a seguir.

\section{a) Uso de testes de laboratório}

Nessa categoria, enquadram-se os ensaios de pino contra lixa e os ensaios de trilha com lama abrasiva. Devido à sua relativa facilidade de realização e ao seu baixo custo, esses ensaios permitiram varrer os parâmetros relativos aos materiais resistentes ao desgaste, ao mesmo tempo em que se verificaram os efeitos devidos a variáveis operacionais, como dureza e granulometria dos abrasivos, bem como cargas e velocidades. Embora esses ensaios atendam aos requisitos de reprodutibilidade e capacidade de estabelecer rankings de desempenho dos materiais, há fortes razões para se questionar a transferibilidade dos resultados para casos práticos de desgaste de bolas de moinho em aplicações industriais, tendo em vista a grande diferença dos sistemas tribológicos.

\section{b) Uso de bolas marcadas - moinhos industriais}

Nesse caso, incluem-se testes com bolas diferenciadas pelo diâmetro maior do que o das bolas da carga normal do moinho, teste com bolas marcadas por atividade radioativa e testes com bolas marcadas com furos e entalhes. As dificuldades referem-se aos custos de realização e aos problemas metodológicos decorrentes da dificuldade de se controlar as condições dos ensaios. Além disso, só podem ser realizados em um está- gio avançado da negociação entre fornecedor e consumidor dos componentes, não servindo para desenvolvimento, mas apenas para aprovação ou não de fornecedor.

\section{c) Uso de moinhos de laboratório}

Nesse ensaio, empregam-se moinhos com até cerca de $1 \mathrm{~m}$ de diâmetro, em que se consegue reproduzir o tipo de interação entre corpos e meio abrasivo encontrada na prática, à exceção da intensidade dos impactos. Vantagens em relação aos testes em moinhos industriais são a maior rapidez dos testes e a possibilidade de introduzir e controlar variáveis de operação (tipo e tamanho de grão dos abrasivos, \% de sólidos na polpa, etc.) e relativas ao material resistente ao desgaste, possibilitando o uso desses ensaios para o desenvolvimento dos materiais. Além disso, um tratamento adequado dos resultados pode permitir a obtenção de dados quantitativos relativos à vida dos componentes em serviço.

O Instituto de Pesquisas Tecnológicas do Estado de São Paulo S/A desenvolveu o ensaio de desgaste de bolas em moinho de laboratório, aplicando-o para avaliar o desempenho de FFBAC, durante a moagem de minérios de ferro e de fosfato, talco e de areia de quartzo. Seus resultados foram validados pela realização de ensaios de laboratório e na instalação industrial, na moagem de minério de fosfato. O presente trabalho apresenta os resultados obtidos em um estudo realizado com o objetivo de caracterizar bolas de moinho adquiridas de diferentes fornecedores para dar subsídio técnico às unidades de moagem industriais.

\section{Material e métodos}

O objetivo do trabalho foi a caracterização dos corpos moedores para avaliação desse insumo adquirido de diferentes fornecedores, o qual foi seqüenciado através de três módulos distintos, apresentados a seguir.

- Módulo I - Determinação das curvas de polarização para definição de quantos grupos poderiam ser montados 
sem que houvesse o efeito de corrosão preferencial de algumas bolas e de proteção de outras durante a avaliação do desgaste de corpos moedores, realizado no Módulo III.

- Módulo II - Caracterização química e metalográfica das bolas.

- Módulo III - Ensaio de desgaste para avaliação do desgaste dos corpos moedores em unidade-piloto de moagem e classificação, segundo metodologia desenvolvida pelo IPT. O objetivo dessa etapa foi estabelecer o ranking de desempenho das bolas, em condições tais que os resultados possam ser transferidos para a prática industrial. Foi também realizado um estudo inicial sobre o efeito da adição de inibidor de corrosão.

Foram recebidos seis tipos de corpos moedores (bolas) para ensaio, denominadas de CM1 a CM6 e identificadas por diferentes tipos de marcação através de furos feitos por eletroerosão. De cada lote de bolas, algumas foram selecionadas aleatoriamente e destinadas a ensaios de análise química e corrosão. Os resultados de caracterização de cada tipo de bola são apresentrados na Tabela 1 .

\section{Run in}

O run in refere-se a um período preliminar de moagem e é essencial para se conseguir remover heterogeneidades superficiais das bolas decorrentes dos processos de fundição e tratamento térmico e remover a estrutura coquilhada presente em bolas de algumas composições, nas regiões próximas à superfície. Em alguns casos, a maior parcela de desgaste, durante um ensaio de laboratório, poderia ocorrer nessa região, o que comprometeria a transferibilidade de resultados. Para a realização da etapa de run in, utilizou-se areia com cerca de $74 \%$ de material entre as malhas $0,3 \mathrm{~mm}$ e 0,21 $\mathrm{mm}$. O run in foi realizado num total de 25 horas de moagem em moinho de bolas a seco, com 4 (quatro) intervalos de parada, nos quais era trocada a areia moída por areia nova e as bolas eram limpas e pesadas.

\section{Circuito de moagem I classificação}

Utilizaram-se circuito fechado de moagem contínua a úmido e classificação, conforme apresentado no fluxograma da Figura 1. O moinho de bolas de laboratório, marca Denver, equipado com um medidor eletrônico de potência, foi revestido internamente com uma manta de borracha com $1 \mathrm{~cm}$ de espessura, com o objetivo de minimizar possíveis efeitos de corrosão, decorrentes de interações entre as ligas das bolas e o aço da carcaça. Trabalhou-se em circuito fechado com um ciclone, onde o underflow (grossos) da classificação retornava para a alimentação do moinho e o overflow (finos) era bombeado para uma caixa de decantação, sendo a água retornada ao processo.

A taxa de alimentação nova de minério de ferro com umidade em torno de $8 \%$ do moinho foi de cerca de $74 \mathrm{~kg} / \mathrm{h}$ (base seca) e a malha de moagem foi de 325 mesh (0,044 mm). Como controle de processo, foram utilizadas vazões mássicas e volumétricas e análises granulo- métricas do underflow e overflow do ciclone.

\section{Taxas de desgaste}

No caso de corpos moedores, um parâmetro indicativo de sua durabilidade é a constante cinética de desgaste, relacionada à taxa específica de consumo. A taxa de consumo representa a perda de massa dos corpos moedores em relação a fatores como consumo energético $(\mathrm{g} / \mathrm{kWh})$, tempo de moagem $(\mathrm{g} / \mathrm{h})$ ou toneladas de minério moído (g/t).

O modelo mais amplamente aceito, para caracterizar a cinética de consumo de corpos moedores, em moinhos rotativos, é a lei do desgaste linear, segundo a qual a taxa ou a velocidade de consumo do corpo moedor é diretamente proporcional à sua área superficial exposta aos diversos mecanismos de desgaste. Como conseqüência, a diminuição de diâmetro das bolas com o tempo de moagem é linear. No presente trabalho, a análise do desgaste foi realizada convertendo-se os resultados de perda de massa para variação de diâmetro. Os diâmetros equiva-

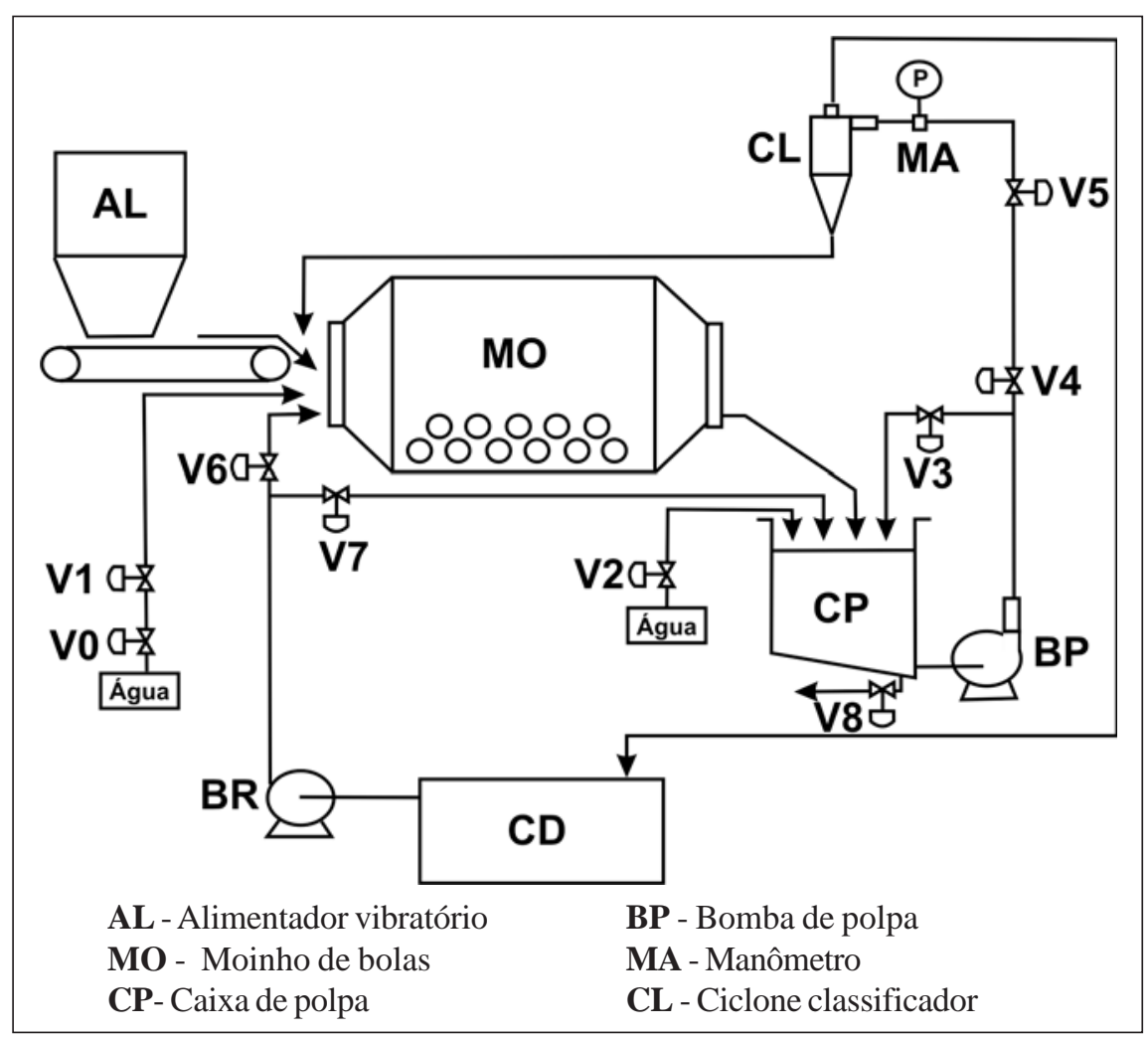

Figura 1 - Fluxograma da planta de moagem de laboratório. 
Tabela 1 - Características dos corpos moedores.

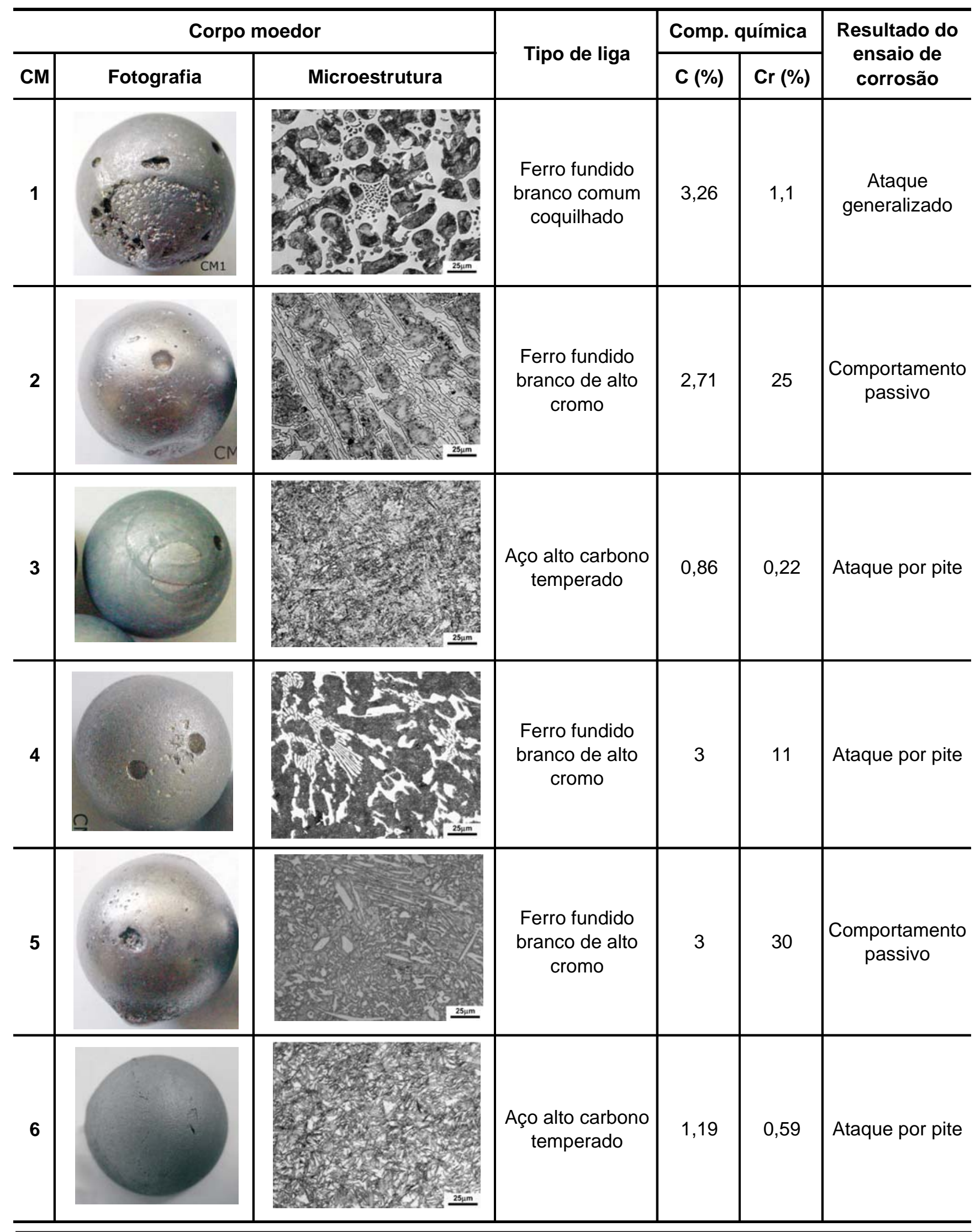

176 REM: R. Esc. Minas, Ouro Preto, 59(2): 173-178, abr. jun. 2006 
lentes foram calculados com as densidade de $7,5 \mathrm{~g} / \mathrm{cm}^{3}$, para as bolas de ferro fundido branco de alto cromo, e de $7,7 \mathrm{~g} / \mathrm{cm}^{3}$, para a bola de aço. Assim, em gráficos de perda de diâmetro pelo tempo de moagem, foram obtidas as taxas de desgaste $\mathbf{k}$, correspondentes aos respectivos coeficientes angulares das retas. Uma vantagem da utilização desse parâmetro é que seu valor não depende do diâmetro original das bolas, ao contrário do que quando se utiliza a perda de massa como indicador da taxa de desgaste. Por uma analogia direta com os processos de cominuição de minerais, é razoável afirmar que a cinética do desgaste seja similarmente dependente da intensidade energética do processo, isto é, de quantos kWh de energia são aplicados para cada tonelada de corpos moedores na carga do moinho. Portanto a potência consumida pelo moinho, durante os ensaios, foi monitorada, e, para cada material, foi calculado o parâmetro Ke, expresso em $\mathrm{g} / \mathrm{kWh}$.

\section{Ensaios de desgaste}

De acordo com os resultados obtidos no Módulo I, referente à caracterização das bolas quanto ao potencial de corrosão, os ensaios de desgaste foram divididos em testes, apresentados a seguir.

- Ensaio D1: realizado com os corpos moedores CM2 e CM5, que apresentaram comportamento passivo no ensaio de corrosão.

- Ensaio D2: realizado com os corpos moedores CM3, CM4 e CM6, que apresentaram ataque por pite no ensaio de corrosão.

- Ensaio D3: realizado com o corpo moedor CM1, que sofreu ataque generalizado no ensaio de corrosão.

- Ensaio D4: realizado com os corpos moedores CM1, CM2, CM4 e CM6, com utilização de inibidor de corrosão.

- Ensaio D5: ensaios complementares para as bolas CM3 e CM6.

- Ensaio D6: ensaios complementares para as bolas CM2 e CM5.

\section{Resultados}

\section{Comparação dos resultados obtidos nos ensaios D1, D2 eD3}

A Figura 2 apresenta o comparativo geral entre as seis famílias de bolas ensaiadas, com as respectivas perdas em massa e diâmetro, bem como suas taxas de desgaste. $\mathrm{O}$ tempo de moagem em cada ensaio foi de cerca de 56 horas.

O corpo moedor CM2 apresentou o melhor desempenho nos ensaios de desgaste em moinho de bolas, seguido do CM4. O pior resultado foi apresentado pelo CM1, com uma taxa de desgaste de $4,7 \mathrm{~mm} / \mathrm{h}$. Os aços conformados mecanicamente (CM3 e CM6) apresentaram desempenho inferior ao dos ferros fundidos de alto cromo.

\section{Ensaio D4}

No ensaio D4, avaliou-se o desempenho dos corpos moedores ao se adici- onar um inibidor de corrosão com um tempo total de moagem de 55 horas. Os corpos moedores avaliados nesse ensaio foram:

- CM1: por ser provavelmente o mais barato entre todos os materiais ensaiados.

- CM2: por ter apresentado o melhor desempenho nos ensaios.

- CM4: por ter apresentado o segundo melhor resultado geral nos ensaios de desgaste; também é relevante que esse material é o de menor teor de cromo, entre os ferros fundidos ligados, sendo, possivelmente, de menor custo.

- CM6: por ter apresentado o melhor resultado entre os aços.

\section{Ensaios D5 e D6}

Os ensaios D5 e D6 são repetições das avaliações de taxas de desgaste para as bolas de aço CM3 e CM6 (ensaio D5) e para as bolas de ferro fundido de alto

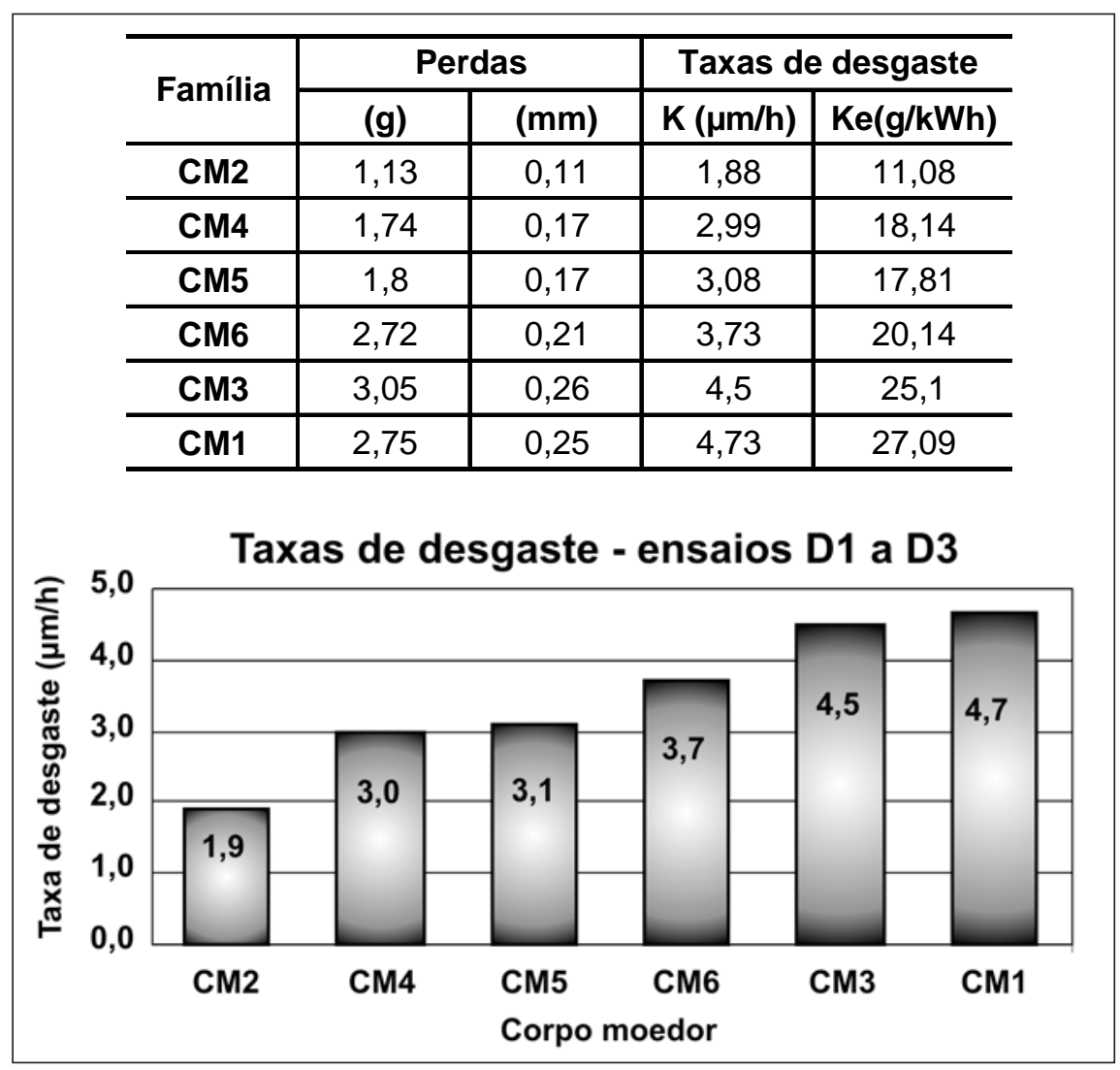

Figura 2 - Comparação entre os diversos corpos moedores. 
cromo CM2 e CM5 (ensaio D6). Com esses ensaios, procurou-se verificar se havia alteração da taxa de desgaste, em relação aos resultados obtidos inicialmente, na medida em que se afastava da superfície original das bolas. Para isso, foi feito um segundo período de run in, com moagem a úmido, contínua, por 40 horas, utilizando-se a areia de fundição descrita anteriormente, seguindo-se o ensaio normal com minério de ferro. No ensaio D5, o tempo total de moagem foi de 23 horas e no, ensaio D6, o experimento foi conduzido por 54,5 horas.

\section{Comparação geral dos resultados de desempenho das bolas}

A Figura 3 apresenta uma comparação do conjunto de resultados. Nesse gráfico, os resultados são apresentados como Fator de Resistência ao Desgaste (FRD), calculado para cada material, tomando-se como referência o desempenho das bolas CM1, no ensaio D3. O FRD de cada material é calculado dividindo-se o valor da taxa de desgaste das bolas CM1 no ensaio D3 pelo valor da taxa de desgaste do material em questão. Dessa forma, o parâmetro FRD indica em que proporção o desempenho de cada material é melhor do que o das bolas CM1. Analisa-se, também, a variação de desempenho em diferentes ensaios para um mesmo material.

\section{Conclusões}

Nos ensaios de desgaste, moendo minério de ferro em escala-piloto, a úmido, em regime contínuo, simulando condições de operação em escala industrial, foram determinadas as taxas de desgaste de bolas de moinho de seis diferentes materiais, compreendendo: um ferro fundido branco comum coquilhado, dois aços alto carbono conformados mecanicamente e temperados e três ferros fundidos de alto cromo. A metodologia dos ensaios permitiu a determinação da redução do diâmetro das bolas com o tempo, obtendo-se as taxas de desgaste expressas como mm/h. Os ensaios mostra-

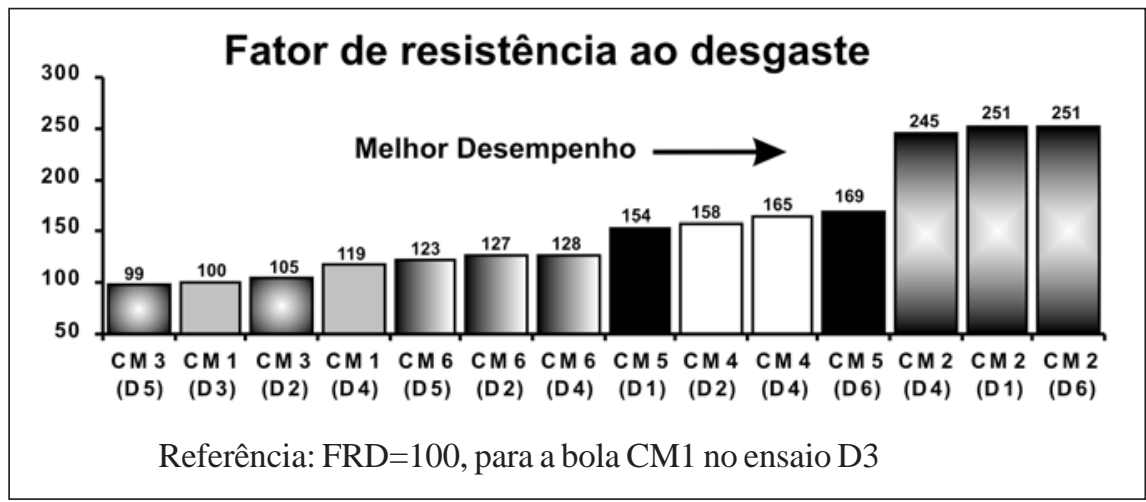

Figura 3 - Comparação do Fator de Resistência ao Desgaste.

ram-se repetitivos, obtendo-se valores de taxas de desgaste praticamente idênticos nos casos em que o mesmo material foi ensaiado duas ou três vezes.

$\mathrm{O}$ ferro fundido branco de alto cromo CM2 apresentou desempenho destacado, com durabilidade cerca de $150 \%$ (2,5 vezes) maior em comparação com o material de pior desempenho. O segundo grupo, em termos de desempenho, também foi constituído por ferros fundidos brancos de alto cromo, os materiais CM4 e CM5, que apresentaram durabilidade entre 50 e $70 \%$ maior em comparação com o material de pior desempenho.

O aço temperado CM6 apresentou desempenho cerca de 25\% maior, em comparação com o material de pior desempenho. Já o resultado do aço CM3 foi comparável ao do material de pior desempenho. $\mathrm{O}$ ferro fundido branco comum coquilhado, CM1, e o aço CM3 foram os materiais de pior desempenho. No caso do ferro fundido comum, esse resultado é a conseqüência esperada de sua menor dureza e menor resistência à corrosão, por sua vez decorrentes da composição química e da microestrutura desse material. Já no caso do aço CM3, o baixo desempenho pôde ser correlacionado com sua fragilidade, que causou o aparecimento de trincas e lascamentos durante os ensaios.

A utilização de um aditivo inibidor de corrosão só produziu efeito significativo no caso do material CM1, ferro fundido branco comum coquilhado. Esse material foi o único que apresentou corrosão generalizada nos ensaios de corrosão.
A partir da medição da potência consumida pelo moinho, durante os ensaios, foi possível determinar, também, taxas de desgaste expressas em termos de $\mathrm{g} / \mathrm{kWh}$. O ranking técnico obtido em laboratório é comparável ao dos testes industriais.

\section{Referências bibliográficas}

INSTITUTO DE PESQUISAS TECNOLÓGICAS. Relatório n74638-205 - Caracterização de corpos moedores-bolas - módulo III - Desgaste de corpos moedores em moinho de bolas. São Paulo: IPT, 2005. (Relatório final).

CASSOLA, M.S. MORAES, S. L., ALBERTIN, A. Ensaio de moagem piloto: referência para avaliação da taxa de desgaste de corpos moedores. Tecnologia em Metalurgia e Materiais, v.1 n2, out-dez. 2004. p2833.

ALBERTIN, E. Efeito da porcentagem de carbonetos $e$ da microestrutura da matriz metálica sobre a resistência ao desgaste de ferros fundidos brancos de alto cromo - ensaios em moinho de bolas. São Paulo: Escola Politécnica, Universidade de São Paulo, 1993. 297p. (Tese de Doutorado).

SEPÚLVEDA, J. Recomendaciones práticas para la evaluacion de cuerpos moledores a escala industrial. In: SIMPÓSIO BRASILEIRO DE MINÉRIO DE FERRO: CARACTERIZAÇÃO, BENEFICIAMENTO E PELOTIZA-ÇÃO, 1. Ouro Preto,1996. Anais... Ouro Preto: ABM,1996. p.595-614.

INSTITUTODE PESQUISAS TECNOLÓGICAS. Relatório n³1.480/93- Ensaios contínuos de moagem para auxílio na avaliação da taxa de desgaste de corpos moedores. São Paulo: IPT, 1993. (Relatório final).

BERALDO, J. L. Moagem de minérios em moinhos tubulares. Cap. 3. Projeto e construção de moinhos de barras e de bolas. p.22-47

CHAVES, A. P., PERES, A. E. C. Teoria e prática do tratamento de minérios. Britagem, peneiramento e moagem. São Paulo: Signus, 1999. p. 562-649.

MASCIA, R. Desenvolvimento e caracterização tribológica de materiais resistentes ao desgaste abrasivo para a indústria mineradora de cassiterita. Uberlândia: Universidade Federal de Uberlândia, 2002. 141p. (Dissertação de Mestrado).

\section{Artigo recebido em 07/12/2005 e} aprovado em 06/04/2006. 